Supporting Information for:

\title{
Enzymatic Synthesis of a Ring-Contracted Analogue of 5-Enolpyruvyl-shikimate-3-Phosphate
}

Ming An‡ and Paul A. Bartlett*

Center for New Directions in Organic Synthesis, + Department of Chemistry, University of California, Berkeley, California 94720-1460

e-mail: paul@fire.cchem.berkeley.edu

‡ current address: Department of Pharmaceutical Chemistry, Box 2280,

University of California, San Francisco, California 94143-2280

$+\quad$ The Center for New Directions in Organic Synthesis is supported by Bristol-Myers Squibb as a Sponsoring Member and Novartis Pharma as a Supporting Member.

${ }^{1} \mathrm{H}-N M R$ of EP-2-P
${ }^{13} \mathrm{C}-\mathrm{NMR}$ of EP-2-P
${ }^{31} \mathrm{P}-\mathrm{NMR}$ of EP-2-P 


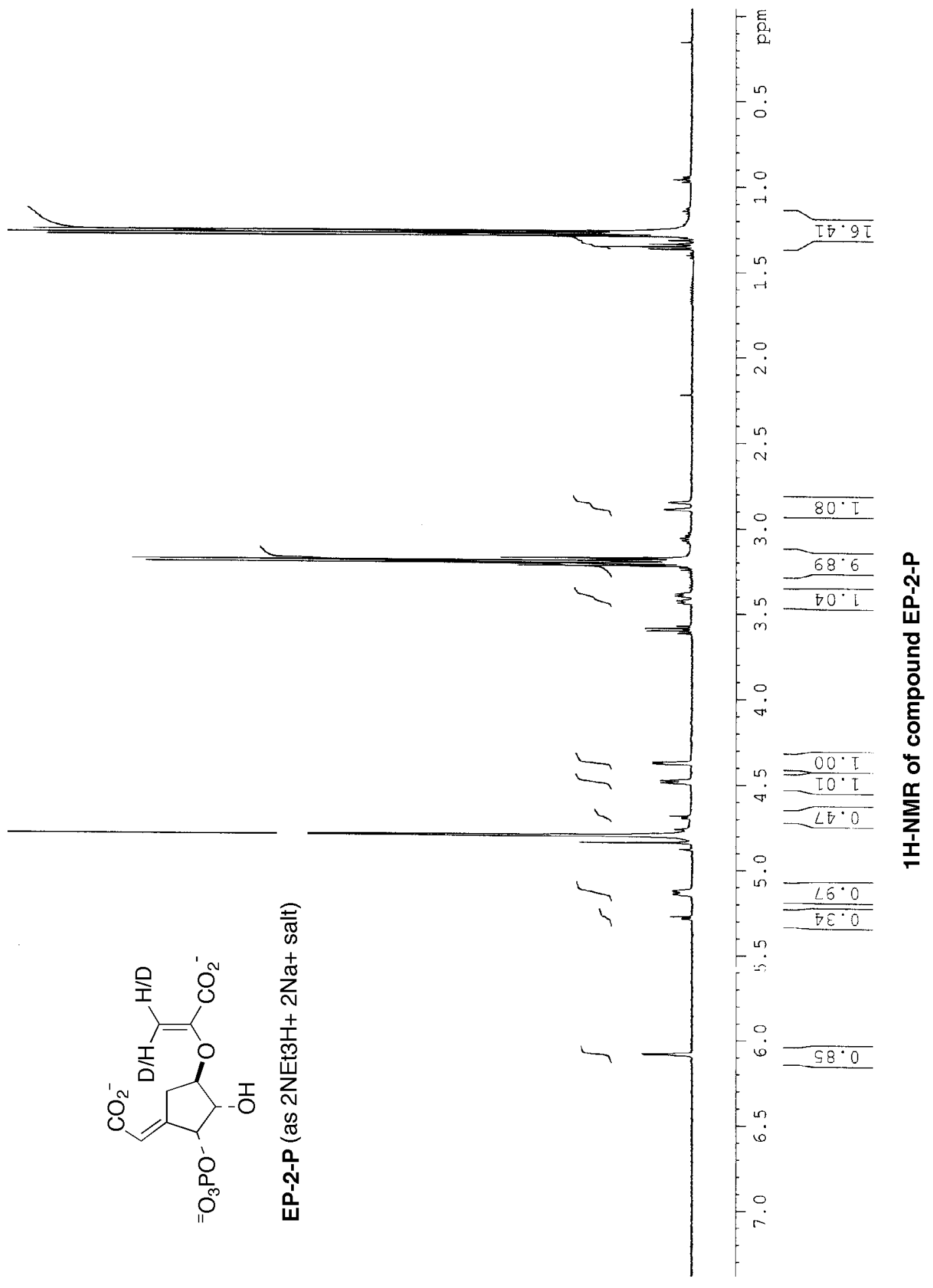




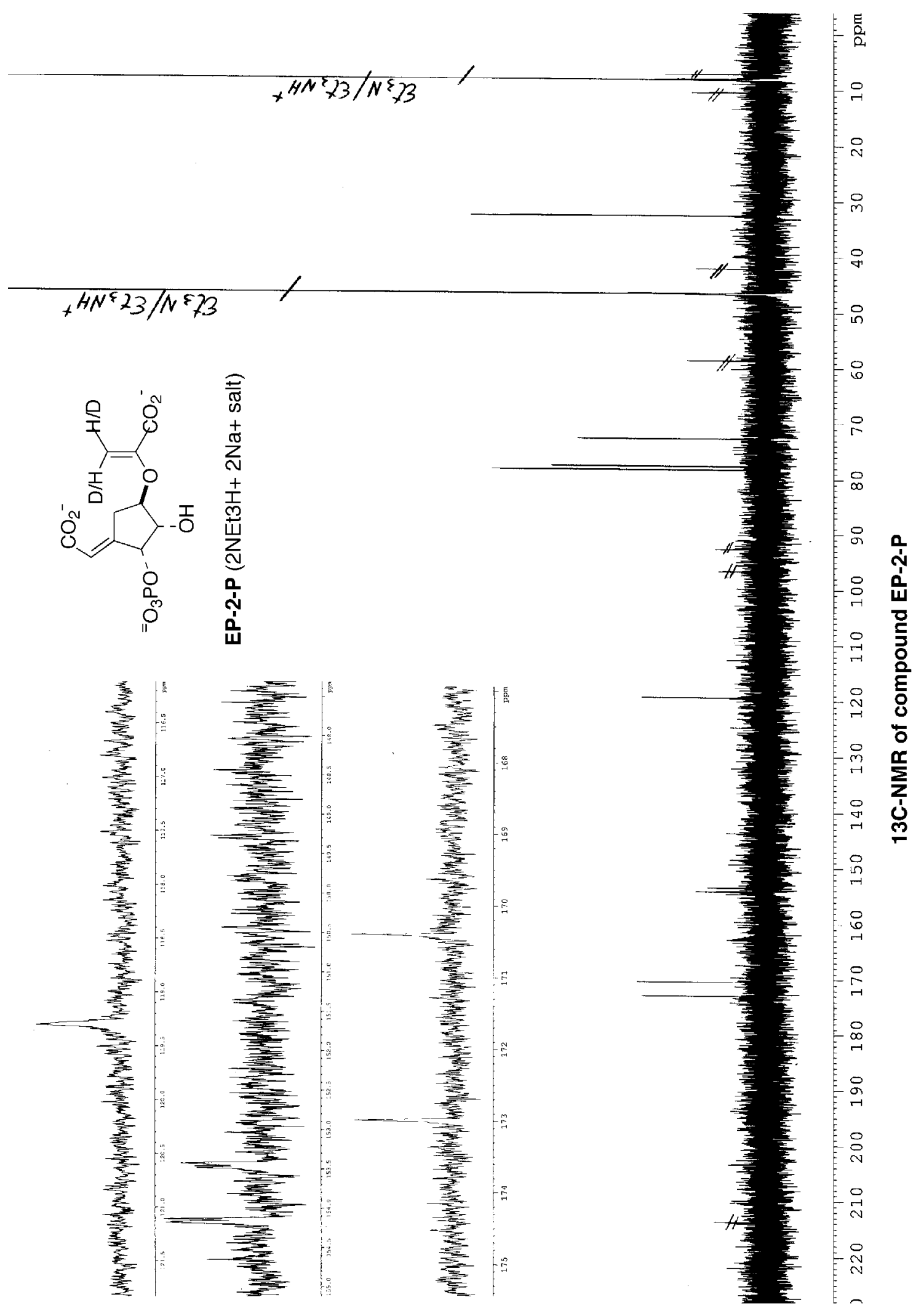




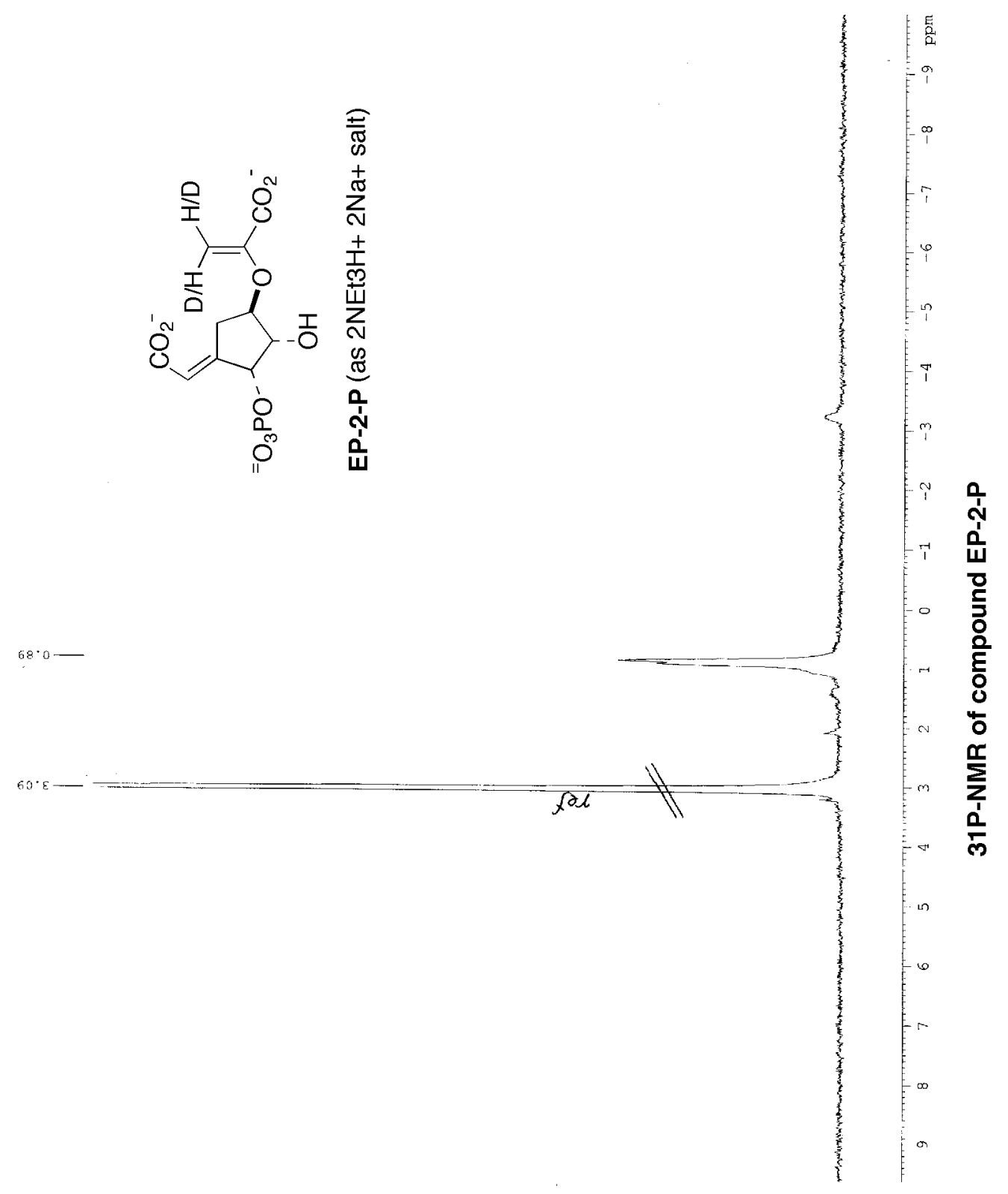

